\title{
A Two-Week Nitazoxanide-Based Quadruple Treatment as a Rescue Therapy for Helicobacter Pylori Eradication
}

\author{
Ali A. Waheeb ${ }^{1}$, Ahmed O. Dorrah ${ }^{1}$, Waleed M. Mousa ${ }^{1}$, \\ Alaa M. Ebrahim ${ }^{2}$ \\ ${ }^{1}$ Tropical Medicine and Gastroenterology Department- Al Azhar University, \\ ${ }^{2}$ Tanta University \\ Corresponding author: Ali Ahmed Waheeb, Email: aliwahib@hotmail.com, mobile: +201223442516
}

\begin{abstract}
Introduction: Helicobacter pylori is the most common prevalent chronic human bacterial infection estimated in $50 \%$ of the global population but only induces clinical diseases in 10-20\% of infected individuals. These include peptic ulcers, acute and atrophic gastritis, intestinal metaplasia, gastric adeno-carcinoma and gastric Bcell lymphoma. H. pylori infection has become highly resistant to traditional first-line treatment regimens because of antibiotic resistance coupled with poor patient compliance with completing the treatment course. Many clinical studies proved that nitazoxanide (NTZ) was found to be well tolerated by humans, with an encouraging rate of eradication when it was administered with omeprazole.

Aims: The aim of the work is to compare between the efficacy of traditional triple therapy and nitazoxanidebased quadruple therapy in treatment of $\mathrm{H}$. pylori and to evaluate the efficacy of nitazoxanide-based regimens as a rescue regimen for $\mathrm{H}$. pylori eradication in resistant patients.

Methodology: This study was carried out on 85 Helicobacter pylori (H. pylori) infected patients; Patients were classified in to 3 groups: Group 1: 60 patients with positive H. pylori Ag taking 14 days triple therapy composed of amoxicillin (1 gm twice daily), clarithromycin (500 mg twice daily) and omeprazole (40 mg once daily).; Group 2: 25 patients with positive H. pylori Ag (naïve: not having previously taken or received a particular treatment for $\mathrm{H}$. pylori) taking 14 days quadruple therapy composed of nitazoxanide (500 mg twice daily), in addition to triple therapy.; Group 3: 22 patients with positive H. pylori Ag after treatment (resistant for triple therapy from group 1) taking 14 days nitazoxanide-based quadruple therapy.

Results: This work recorded the best results for H. pylori eradication (92\%) in group II who received nitazoxanide based quadruple therapy compared with group I eradication rate $(63.3 \%)$, who received traditional triple therapy regimen and better results (77.3\%) in group III (resistant patients from group I).

Conclusion: This study could state that, using nitazoxanide can overcome traditional triple therapy resistance; in addition to its efficacy in treating naïve patients who didn't take any medical treatment for H. pylori.

Recommendations: Nitazoxanide (NTZ) based regimen namely NTZ/ clarithromycin / PPIs and amoxicillin is a recommended $\mathrm{H}$. pylori therapeutic regimen in our community.
\end{abstract}

Keywords: Helicobacter-Pylori, Nitazoxanide.

\section{INTRODUCTION}

Helicobacter pylori (H. pylori) is a small, Gram-negative spirochete inhabiting the mucous layer overlying the gastric epithelial cells in humans. It is the most common prevalent chronic human bacterial infection estimated in $50 \%$ of the global population ${ }^{(1)}$.

H. pylori only induces clinical diseases in 10$20 \%$ of infected individuals. These include peptic ulcers, acute and atrophic gastritis, intestinal metaplasia, gastric adeno-carcinoma and gastric B-cell lymphoma ${ }^{(2)}$.

Furthermore, according to the World Health Organization, $\mathrm{H}$. pylori is classified as a type 1 carcinogen and is the primary cause of peptic ulcer disease, gastric carcinoma, and mucosa-associated lymphoid tissue lymphomas (MALT) ${ }^{(3)}$.

Current $H$. pylori infection preferred treatment involves; proton pump inhibitor (PPI)based triple or quadruple regimens ${ }^{(4)}$.
However, a study based on the Maastricht EQ guidelines, indicated that treatment with a PPIbased triple regimen as first-line therapy will fail in $\sim 30 \%$ of patients on an intention-to-treat (ITT) basis, and will fail in $\sim 50 \%$ of patients who are treated with PPI-based triple regimen with Metronidazole ${ }^{(5)}$.

H. pylori infection has become highly resistant to traditional first-line treatment regimens because of emerging antibiotic resistance coupled with poor patient compliance with completing the treatment course that decrease $\mathrm{H}$. pylori eradication rates. So there is a considerable interest in evaluating new antibiotic combinations and regimens ${ }^{(6)}$.

Nitazoxanide (NTZ) is an antibiotic with microbiological characteristics similar to those of metronidazole with nearby cost. It was settled as a therapy having a broad spectrum of activity against micro-aerobic and anaerobic bacteria, anaerobic protozoa, and helminthes ${ }^{(7)}$. 
Many clinical in vivo and in vitro studies proved that Nitazoxanide (NTZ) was found to be well tolerated by humans, with an encouraging rate of eradication of $\mathrm{H}$. pylori when it was administered with omeprazole ${ }^{(8)}$.

NTZ was used as a mono-therapy, as it was a new drug that was unlikely to be affected by the antibiotic resistance of strains in patients who had previous failed therapies. The partial success of NTZ as a single-agent therapy would be an excellent base for further studies of combination therapy ${ }^{(9)}$.

\section{AIM OF THE WORK}

The aim of the work is to compare between the efficacy of traditional triple therapy and nitazoxanide-based quadruple therapy in treatment of H. pylori and to evaluate the efficacy of nitazoxanide-based regimens as a rescue regimen for $\mathrm{H}$. pylori eradication in resistant patients.

\section{PATIENTS AND METHODS}

This work was carried out on 115 patients with dyspeptic symptoms (patients selected within two months) who were enrolled from Tropical Medicine Department at El-Hussein and El- Sayed Galal University Hospitals.

Selection of patients in whom H. pylori induced GIT disease was confirmed by positive (+ve) H. pylori monoclonal stool antigen test and positive $\mathrm{H}$. pylori biopsy (Giemsa stain) on upper GIT endoscopy.

Firstly the enrolled 115 patients were tested for $\mathrm{H}$. pylori prevalence recording a high $\mathrm{H}$. pylori prevalence rate $(105 / 115,91.3 \%)$.

The recorded high frequency of $\mathrm{H}$. pylori infection in this study, with upper gastrointestinal tract related symptoms and documented gastritis could be due to the fact that El-Hussein and El-Sayed Galal University Hospitals are receiving a wide range of population with a relatively poor socioeconomic status and overcrowded conditions.

Then $20 \mathrm{H}$. pylori cases were excluded; 12 refused the participation, and 8 cases didn't meet the inclusion criteria (History of previous $\mathrm{H}$. pylori treatment, pregnant women and known allergy to medication included in the study).

Eighty five $\mathrm{H}$. pylori patients were included in the research and randomly distributed into two groups according to the received regimens of therapy for $\mathrm{H}$. pylori.
Group I (60 patients) who received the traditional treatment regimen of amoxicillin (1gm twice daily), clarithromycin (500 $\mathrm{mg}$ twice daily) and omeprazole (40 mg once daily) for 14 days. A case of clarithromycin allergy appeared within the study as a dermatological rash, stopped treatment and replaced with another case.

A case of amoxicillin associated diarrhea (for 5 days) appeared within the study, stopped treatment and replaced with another case.

Group II (25 patients) who received $\mathrm{H}$. pylori treatment regimen of nitazoxanide $(500 \mathrm{mg}$ twice daily), omeprazole (40mg once daily), clarithromycin (500 mg twice daily) and Amoxicillin (1gm twice daily) for 14 days.

Regarding sex and age; 48 males and 37 females were included in the study with males were slightly more than females. Sex distributions among the three studied groups were ( 35 males and 25 females) in group I and (13 males and 12 females) in group II.

Inclusion criteria: 1. Patients with dyspeptic symptoms undergoing upper gastrointestinal tract (GIT) endoscopy selecting HP infected patients to be recruited for the study. 2. Patients must have had Helicobacter Pylori infection confirmed by H. pylori monoclonal stool antigen.

Exclusion Criteria: 1. Active GIT bleeding. 2. Recent use of antibiotics (within 6 weeks). 3. Pregnancy and lactating women. 4. Previous treatment for HP. 5. Recent use of PPI within 2 weeks. 6. Allergy to any medication included in the study.

Initial evaluation: All the studied subjects were subjected to: Complete history taking and clinical assessment: Stressing on symptoms of upper gastrointestinal tract (GIT) disorders e.g. nausea, vomiting, epigastric pain, heart burn, eructation, fullness, dyspepsia, hematemesis or melena. Full general and abdominal examinations. 2- Laboratory evaluation: Complete blood count (CBC). Liver function tests: alanine aminotransferase (ALT), aspartate aminotransferase (AST), albumin, prothrombin time and INR. Renal function tests: S. urea and S. creatinine. 3- Stool H. pylori antigen: The test was done at start of study and 6 weeks after completion of therapy for both groups (1 and 2). 4Esophagogastroduodenoscopy and biopsy was taken for histopathology for detection of $\mathrm{H}$. pylori infection: The endoscopy was done at start of study and 6 weeks after completion of therapy for both groups (1 and 2). 5- Urea Breath Test: The test was done 6 
weeks after completion of therapy for group 3 (patients in whom triple therapy failed).

\section{Ethical Aspects:}

I. Approving protocol: Current protocol was approved by Committee of Tropical Medicine Department and Committee of Faculty of Medicine at Al-Azhar University, and then by the ethical committee at Al-Azhar University.

II. Patient Consent: All patients that were included in current study signed an approved consent from Al-Azhar University Ethical Committee.

\section{Statistical Analysis:}

Data were analyzed using Statistical Program for Social Science (SPSS) version 15.0. Quantitative data were expressed as mean \pm standard deviation (SD). Qualitative data were expressed as frequency and percentage. Probability (P-value). P-value $<0.05$ was considered significant. $\mathrm{P}$-value $<0.001$ was considered as highly significant. P-value $>0.05$ was considered insignificant.

\section{RESULTS}

Table (1): Main clinical data in all dyspeptic patients in the studied groups.

\begin{tabular}{|l|c|c|c|}
\hline \multicolumn{1}{|c|}{ Mean Clinical data } & $\begin{array}{c}\text { Group (I) } \\
{[\mathbf{N = 6 0 ]}}\end{array}$ & $\begin{array}{c}\text { Group (II) } \\
{[\mathbf{N = 2 5 ]}}\end{array}$ & p-value \\
\hline Regurgitation & $20(33.3 \%)$ & $7(28 \%)$ & $>0.05$ \\
\hline Nausea/ vomiting & $17(28.3 \%)$ & $6(24 \%)$ & $>0.05$ \\
\hline
\end{tabular}

This table shows no statistically significant difference between groups according to mean clinical data.

Table (2): Pretreatment endoscopic findings in the studied groups.

\begin{tabular}{|l|c|c|c|}
\hline \multicolumn{1}{|c|}{ Endoscopic findings } & $\begin{array}{c}\text { Group (I) } \\
{[\mathbf{N = 6 0 ]}}\end{array}$ & $\begin{array}{c}\text { Group (II) } \\
{[\mathbf{N = 2 5 ]}}\end{array}$ & p-value \\
\hline Pan-gastritis & $40(66.7 \%)$ & $18(72 \%)$ & $>0.05$ \\
\hline Duodenal ulcer & $12(20 \%)$ & $5(20 \%)$ & $>0.05$ \\
\hline Gastric ulcer & $8(13.3 \%)$ & $3(12 \%)$ & $>0.05$ \\
\hline
\end{tabular}

This table shows no statistically significant difference between groups according to endoscopic findings.

Table (3): Comparison between groups according to post treatment $\mathrm{H}$. pylori stool antigen results.

\begin{tabular}{|c|c|c|c|}
\hline $\begin{array}{c}\text { Post treatment H. pylori } \\
\text { stool antigen results }\end{array}$ & $\begin{array}{c}\text { Group (I) } \\
{[\mathrm{N}=60]}\end{array}$ & $\begin{array}{c}\text { Group (II) } \\
{[\mathrm{N}=25]}\end{array}$ & p-value \\
\hline Positive & $22(36.7 \%)$ & $2(8 \%)$ & \multirow{2}{*}{$<0.008^{*}$} \\
\hline Negative & $38(63.3 \%)$ & $23(92 \%)$ & \\
\hline
\end{tabular}

*p-value $<0.05 \mathrm{~S}$

This table shows statistically significant difference between groups according to post treatment $\mathrm{H}$. pylori stool antigen results.
Table (5): Comparison between groups according to endoscopic findings post treatment.

\begin{tabular}{|l|c|c|c|}
\hline \multicolumn{1}{|c|}{ Endoscopic findings } & $\begin{array}{c}\text { Group (I) } \\
{[\mathbf{N = 6 0 ]}}\end{array}$ & $\begin{array}{c}\text { Group (II) } \\
{[\mathbf{N = 2 5}}\end{array}$ & p-value \\
\hline Pan-gastritis & $23(38.3 \%)$ & $3(12 \%)$ & $0.016^{*}$ \\
\hline Duodenal ulcer & $8(13.3 \%)$ & $1(4 \%)$ & $>0.05$ \\
\hline Gastric ulcer & $3(5 \%)$ & $1(4 \%)$ & $>0.05$ \\
\hline
\end{tabular}

*p-value $<0.05 \mathrm{~S}$

This table shows statistically significant difference between groups according to pan-gastritis.

Table (6): Comparison between groups according to post therapeutic regimens clinical data.

\begin{tabular}{|l|c|c|c|}
\hline $\begin{array}{c}\text { Post therapeutic regimens } \\
\text { clinical data }\end{array}$ & $\begin{array}{c}\text { Group (I) } \\
{[\mathbf{N = 6 0 ]}}\end{array}$ & $\begin{array}{c}\text { Group (II) } \\
{[\mathbf{N}=\mathbf{2 5}]}\end{array}$ & p-value \\
\hline Dyspepsia & $25(41.7 \%)$ & $5(20.0 \%)$ & $>0.05$ \\
\hline Nausea/ vomiting & $13(21.7 \%)$ & $2(8.0 \%)$ & $>0.05$ \\
\hline Regurgitation & $7(11.7 \%)$ & $2(8.0 \%)$ & $>0.05$ \\
\hline
\end{tabular}

This table shows no statistically significant difference between groups according to dyspepsia.

Table (7): Post treatment urea breath test results distribution in the group III.

\begin{tabular}{|l|c|c|}
\hline \multirow{2}{*}{$\begin{array}{c}\text { Post treatment urea breath test } \\
\text { results }\end{array}$} & \multicolumn{2}{|c|}{ Group (III) [22] } \\
\cline { 2 - 3 } & No. & \% \\
\hline Positive (Resistant) & 5 & $22.7 \%$ \\
\hline Negative (Cured) & 17 & $77.3 \%$ \\
\hline
\end{tabular}

This table shows that the positive $(22.7 \%)$ and negative $(77.3 \%)$ of post treatment urea breath test results.

Table (8): Post therapeutic regimen clinical data in Group (III).

\begin{tabular}{|l|c|c|}
\hline \multirow{2}{*}{ Post therapeutic regimen clinical data } & \multicolumn{2}{|c|}{ Group (III) [22] } \\
\cline { 2 - 3 } & No. & $\%$ \\
\hline Dyspepsia & 6 & $27.3 \%$ \\
\hline Nausea/ vomiting & 3 & $13.6 \%$ \\
\hline Regurgitation & 3 & $13.6 \%$ \\
\hline
\end{tabular}

This table shows that the dyspepsia (27.3\%), nausea/vomiting (13.6\%) and regurgitation (13.6\%) of post therapeutic regimen clinical data.

Table (9): Comparison between groups according to (Results).

\begin{tabular}{|l|c|c|c|c|}
\hline & $\begin{array}{c}\text { Group (I) } \\
{[\mathbf{N = 6 0 ]}}\end{array}$ & $\begin{array}{c}\text { Group } \\
\text { (II) } \\
{[\mathbf{N}=25]}\end{array}$ & $\begin{array}{c}\text { Group } \\
\text { (III) [22] }\end{array}$ & \multirow{2}{*}{ p-value } \\
\hline Positive (Resistant) & $22(36.7 \%)$ & $2(8 \%)$ & $5(22.7 \%)$ & \multirow{2}{*}{$0.022 *$} \\
\hline Negative (Cured) & $38(63.3 \%)$ & $23(92 \%)$ & $17(77.3 \%)$ & \\
\hline
\end{tabular}

*p-value $<0.05 \mathrm{~S}$

This table shows statistically significant difference between groups according to ((RESULTS)), while group II and III non-significant. 


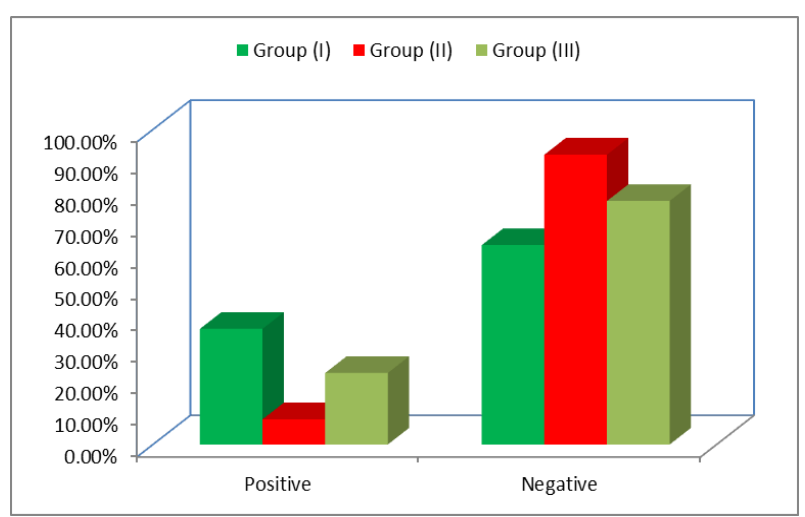

Fig (1): Bar chart between groups according to ((Results)).

\section{DISCUSSION}

Helicobacter pylori is one of the most common, medically prominent infection worldwide and one of the major causative factor of peptic ulcer disease. So, eradication of $\mathrm{H}$. pylori is effective in healing ulcers and reducing the ulcer recurrence, eliminating the need for maintenance therapy ${ }^{(\mathbf{1 0})}$.

Besides being a major etiological factor in peptic ulcer disease, there is some evidence that it may also be associated with other gastric diseases, and also was listed as a class 1 carcinogen ${ }^{(11)}$.

H. pylori is not easy to eradicate. Factors such as the bacterial resistance and difficulty achieving bactericidal concentrations in the gastric mucosa contribute to the variable response to antibiotic therapy. As a result, triple and quadruple pharmacotherapy regimens are now used to ensure high eradication rates ${ }^{(\mathbf{1 2})}$.

Epidemiological studies have indicated that the incidence of new infections in developing countries is 3 to 10 percent of the population per year. Overcrowding, poor sanitation, and low economic standards are the risk factors for $H$. pylori infection, which is inversely correlated with the socioeconomic status ${ }^{(\mathbf{1 3})}$.

There are several methods available to detect H. pylori infection including invasive methods based on gastric biopsies and non-invasive methods like serology, urea breath tests (UBTs), and stool antigen tests. Stool antigen tests, which have been used in this study, have recently been welcomed with great expectations as they are convenient to the patients and can be easily performed even in small laboratories with a reported high accuracy ${ }^{(\mathbf{1 4})}$.

H. pylori eradication reduces the lifetime risk of peptic ulcer disease and possibly of gastric cancer. Patients with active gastric or duodenal ulcers or a documented history of ulcer should be tested for H. pylori infection and treated if found to be infected. First-degree relatives of those with a gastric cancer history should also be tested and treated if positive. Testing for and treatment of $\mathrm{H}$ pylori infection are recommended for low-grade gastric MALT lymphoma and following resection of early gastric cancer ${ }^{(\mathbf{1 5})}$.

The wide spread and sometimes indiscriminate use of antibiotics in developing countries has resulted in a higher prevalence of $\mathrm{H}$. pylori treatment failure depending on antimicrobial resistance ${ }^{(\mathbf{1 6})}$.

Nitazoxanide, is a cheap compound with a spectrum of activity similar to that of metronidazole but without the problem of resistance ${ }^{(\mathbf{1 7})}$.

In this study, we tried to determine the prevalence of $\mathrm{H}$. pylori as well as comparing between the current and new nitazoxanide (NTZ) based therapeutic regimens for Helicobacter pylori (H. pylori) infection to overcome the problem of resistance with the current regimens.

On history taken from the studied groups, the reported suspected injurious agents for their GIT disorders were out door fast food, smoking, non-steroidal anti-inflammatory drugs (NSAIDS) and caffeine with percentages of $\mathbf{3 0 \%}, \mathbf{2 5 \%}$, $21.7 \%, 15 \%)$ in group I and $(24 \%, 8 \%, 24 \% \&$ $\mathbf{1 2 \%}$ ) in group II without statistically significant difference between the studied groups.

These reported suspected injurious agents for the studied patients' disorders are agreed with Laine et al. and Begovic and Selmani ${ }^{(18,19)}$.

The patients' endoscopic appearance was pan-gastritis, duodenal ulcers and gastric ulcers with a percentage of $(66.7 \%, 20 \% \& 13.3 \%)$ in group I and $(\mathbf{7 2} \%, \mathbf{2 0} \%$ \& $12 \%)$ in group II, $\mathrm{H}$. pylori infection almost always causes chronic active gastritis.

Helicobacter pylori eradication results as evaluated by $H$. pylori monoclonal stool antigen, 6 weeks post therapeutic regimens reported that eradication rate was $\mathbf{6 3 . 3 \%}$ (38 patients) in group I and $92 \%$ (23 patients) in group II with statistically significant difference between the studied groups.

We tried in this study to introduce nitazoxanide as an anti-microbial drug to overcome H. pylori resistance to the currently used antimicrobial agents. 
So the 22 resistant cases of group I were included in group III and received nitazoxanide based quadruple therapy composed of nitazoxanide (500 mg twice daily), omeprazole (40 mg once daily), clarithromycin (500 mg twice daily) and Amoxicillin (1 gm twice daily) for 14 days.

Helicobacter pylori eradication results in group III as evaluated by urea breath test, 6 weeks post therapeutic regimens reported that eradication rate was $\mathbf{7 7 . 3 \%}$ (17 patients).

Regarding post treatment complaints in group III; $(27.3 \%)$ of patients remained having dyspepsia, (13.6\%) had Nausea/vomiting and $(13.6 \%)$ had regurgitation.

So this work recorded the best results for H. pylori eradication (92\%) in group II who received nitazoxanide based quadruple therapy compared with group I eradication rate (63.3\%), who received traditional triple therapy regimen and better results $(77.3 \%)$ in group III (resistant patients from group I).

Group I who received clarithromycin, omeprazole and amoxicillin regimen achieved the least eradication rate $\mathbf{6 3 . 3 \%}$ ) with a lot of residual complaints.

These results agreed with Yakoob et al. ${ }^{(20)}$ who reported that patients were treated with omeprazole (40 mg daily), clarithromycin (CLR) $(500 \mathrm{mg})$ and amoxicillin (AMX) (1g twice a day) for 14 days. A 14 C-urea breath test (14 C-UBT) was repeated four weeks after completion of treatment to confirm eradication. Triple therapy failure was seen in 30/92 (33\%) patients. The resistance rates were: CLR 33\% (30/92 and AMX 2\% (2/92).

Also agreed with Kobtan et al. ${ }^{(21)}$ who reported that A 370 patients infected with $\mathrm{H}$ pylori received the standard triple therapy (PPI twice daily, $500 \mathrm{mg}$ clarithromycin twice daily and either $1 \mathrm{~g}$ amoxicillin or $500 \mathrm{mg}$ metronidazole twice daily for 2 weeks). Eradication was successful in only 223 patients $(60.27 \%)$ raising questions if $\mathrm{H}$ pylori is still responding to standard triple therapy.

The present results also agreed with Malfertheiner et al. ${ }^{(22)}$ who stated that in areas of low clarithromycin resistance, including the United States, a 14-day course of "triple therapy" with an oral proton pump inhibitor, clarithromycin $500 \mathrm{mg}$, and amoxicillin $1 \mathrm{~g}$ (or, if penicillin allergic, metronidazole $500 \mathrm{mg}$ ), all given twice daily for 14 days, is still recommended for first-line therapy. This regimen only achieves rates of eradication in up to $70 \%$ of cases.

The present results are disagreed with the study reported by Higuchi et al. ${ }^{(23)}$ who stated that H. pylori eradication rates were $80 \%(116 / 145$ patient) who received the high-dose group (omeprazole $40 \mathrm{mg} /$ day + amoxicillin $2 \mathrm{gm} /$ day + clarithromycin $800 \mathrm{mg} /$ day).

Group II who received nitazoxanide, clarithromycin, omeprazole and amoxicillin regimen achieved the best eradication rate $\mathbf{( 9 2 \% )}$ with a minimal residual complaints.

These results agreed with Shehata et al. ${ }^{\text {(24) }}$ who reported that the response to treatment of nitazoxanide was significantly higher than traditional treatment regimen. One hundred and six cases $(94.6 \%)$ of 112 patients who completed the study showed complete cure, while only 63 cases $(60.6 \%)$ of 104 patients (received triple therapy) showed the same response.

H. pylori infection has become highly resistant to the traditional first-line treatment regimens because of emerging antibiotic resistance coupled with poor patient compliance with completing the treatment course that decrease $\mathrm{H}$. pylori eradication rates. So there is a considerable interest in evaluating new antibiotic combinations and regimens.

\section{CONCLUSION}

This study could state that, using nitazoxanide can overcome traditional triple therapy resistance; in addition to its efficacy in treating naïve patients who didn't take any medical treatment.

\section{RECOMMENDATIONS}

Improving the standard of living, socioeconomic status, environmental sanitation and personal hygiene are important for elimination and personal H. pylori infection.

H. pylori eradication should be confirmed to accelerate the healing and prevent relapse in PUD as well as GIT malignancies; as $\mathrm{H}$. pylori is classified as a class 1 carcinogen by IARC and WHO.

Nitazoxanide (NTZ) based regimen namely NTZ/ Clarithromycin / PPIs and Amoxicillin is a recommended $\mathrm{H}$. pylori therapeutic regimen in our community. 


\section{REFERENCES}

1. Malfertheiner P, Megraud F, O'Morain C et al. (2012): Management of Helicobacter pylori infection-the Maastricht IV/Florence. Consensus. Report. Gut., 61 (5): 646-64.

2. Proenca-Modena JL, Acrani GO and Brocchi M (2009): Helicobacter-pylori: phenotypes, genotypes and virulence genes. Future Microbiol., 4 (2):223-40.

3. Houghton $J$ and Wang TC (2005): Helicobacter pylori and gastric cancer: a new paradigm for inflammation-associated epithelial cancers. Gastroenterol., 128(6): 1567-78.

4. Chey WD and Wong BC (2007): American College of Gastroenterology guideline on the management of Helicobacter pylori infection. Am J Gastroenterol., 102: 1808-25

5. Dore MP, Leandro G, Realdi G et al. (2000): Effect of pre-treatment antibiotic resistance to metronidazole and clarithromycin on outcome of Helicobacter pylori therapy: a metaanalytical approach. Dig Dis Sci., 45(1):68-76.

6. Duck WM, Sobel J, Pruckler JM et al. (2004): Antimicrobial resistance incidence and risk factors among Helicobacter pyloriinfected persons, United States. Emerg Infect Dis., 10:1088-94.

7. Parashar $A$ and Arya $R$ (2005): Nitazoxanide. Indian Pediatr; 42(11): 1161-65.

8. Hoffman PS, Sisson G, Croxen MA et al. (2007): Antiparasitic-drug-nitazoxanide inhibits the pyruvate oxidoreductases of Helicobacter pylori, selected anaerobic bacteria and parasites, and Campylobacter jejuni. Antimicrob Agents Chemother., 51(3):868-76.

9. Graham DY\& Fischbach L (2010): Helicobacter pylori infection. N Engl J Med; 363(6):595-96.

10. Lanas A, Chan FK (2017): Peptic ulcer disease. Lancet, 390(10094):613-24.

11. Trikudanathan G, Philip, Dasanu CA et al. (2011): Association between Helicobacter pylori infection and pancreatic cancer. JOP; 12(1):26-31.

12. Gisbert JP, Calvet $X$ (2012): Update on nonbismuth quadruple (concomitant) therapy for eradication of Helicobacter pylori. Clin Exp Gastroenterol., 5:23-34.

13. Khalifa MM, Sharaf RR \& Aziz RK (2010): Helicobacter pylori: a poor man's gut pathogen. Gut pathogens, 2(2): 1-12.
14. Malfertheiner P, Megraud F, O'Morain C et al. (2002): Current concepts in the management of Helicobacter pylori infectionthe Maastricht 2-2000 Consensus Report. Aliment Pharmacol Ther.,16:167-80.

15. Miwa H, Go MF, Sato N (2002): H.pylori and gastric cancer: the Asian enigma. Am J Gastroenterol; 97(5):1106-12.

16. Gerrits MM, van Vliet AH, Kuipers EJ et al. (2006): H.pylori and antimicrobial resistance: molecular mechanisms and clinical implications. Lancet Infect Dis.,6:699-709.

17. Guttner $Y$, Helen MW, Charlie $\mathrm{V}$ et al. (2003): Nitazoxanide in Treatment of Helicobacter pylori: a Clinical and In Vitro Study. Antimicrob Agents Chemother., 47(12): 3780-83.

18. Laine L, Yang H, Chang SC et al. (2012): Trends for incidence of hospitalization and death due to GI complications in the United States from 2001 to 2009. Am J Gastroenterol; 107:1190.

19. Begovic $G$ and Selmani $R$ (2015): Etiological Factors in Urgent Gastroduodenal Ulcer. Pril (Makedon Akad Nauk Umet Odd Med Nauki); 36(2):203-10.

20. Yakoob J, Abid S, Abbas $Z$ et al. (2010): Antibiotic susceptibility patterns of Helicobacter pylori and triple therapy in a high-prevalence area. Br J Biomed Sci 2010; 67: 197-201.

21. Kobtan A, Abd Elsalam S, El Kalla F et al. (2016): A Nitazoxanide based treatment versus traditional therapy for Helicobacter pylori eradication: a single center experience. Medicine (Baltimore); 95:e3879.

22. Malfertheiner $P$, Megraud F, O'Morain $\mathrm{C}$ et al. (2012): Helicobacter pylori: clinical management. Curr Opin Gastroenterol; 28(6):608-14.

23. Higuchi, Takama Maekawa, Koichiro Nakagawa, et al. (2006): Clin Drug Investig. 2006; 26(7): 403-14.

24. Mona AH Shehata, Raghda Talaat,Samah Soliman, et al. (2017): Randomized controlled study of a novel triple nitazoxanide (NTZ) containing therapeutic regimen versus the traditional regimen for eradication of Helicobacter pylori infection;76-89. 